\title{
ON EFFICACY AND ACCEPTABILITY OF EARLY MEDICAL ABORTION BY MIFEPRISTONE WITH ORAL OR VAGINAL MISOPROSTOL
}

\author{
Asha Gopi Nath1, Ajay Kumar²
}

${ }^{1}$ Associate Professor, Department of Obstetrics and Gynaecology, Government Medical College, Kottayam.

${ }^{2}$ Associate Professor, Department of Obstetrics and Gynaecology, Government Medical College, Kottayam.

\begin{abstract}
BACKGROUND

Unsafe abortion is a major public health problem. Globally, 20 million unsafe abortions take place each year and account for $13 \%$ of all maternal deaths. According to WHO, 56\% of abortions in developing countries are still unsafe even though medical abortion methods have been in use for more than a decade.

The main objective of the present study is to compare the efficacy, acceptability, side effects and factors affecting outcome of early medical abortion with oral and vaginal misoprostol after oral mifepristone in inducing early medical abortion up to 49 days.
\end{abstract}

\section{MATERIALS AND METHODS}

It was an interventional study (non-RCT) conducted on women requesting termination of early pregnancy at the outpatient department of family planning unit with ultrasound confirmed intrauterine gestation of $\leq 49$ days allocated into two groups. Mifepristone $200 \mathrm{mg}$ was administered on Day 1 followed by $400 \mathrm{mg}$ of oral misoprostol for Group I and $800 \mathrm{mg}$ of vaginal misoprostol for Group II. They were reviewed on Day 14 by ultrasound for completion of abortion and Hb. If abortion was incomplete or bleeding was excessive, curettage was done.

\section{RESULTS}

The two groups were comparable with respect to age, parity and gestational age, socio-economic status and level of education. There was no significant difference in the complete abortion rates for oral (91.1\%) and vaginal (92.0\%). Mean induction abortion interval was 4.29 hours for oral and 3.5 hours for vaginal $(\mathrm{p}=0.023)$. History of previous abortion was found to be a strong predictor of failure of early medical abortion ( $p=0.007)$. Nausea $(24 \%)$, vomiting $(13 \%)$ and fatigue $(50 \%)$ were more in the oral group. Mean duration of bleeding was 9.4 days in oral and 8.2 days in vaginal group $(p=0.000)$. Method satisfaction was more among oral group (92.2\%) compared to $85.1 \%$ in vaginal, but not statistically significant $(\mathrm{p}>0.05)$.

\section{CONCLUSION}

Medical abortion with $200 \mathrm{mg}$ of mifepristone in combination with $400 \mathrm{mg}$ misoprostol orally or 800 mg vaginally after 48 hours was found to be safe, simple, effective, non-invasive and acceptable method.

\section{KEYWORDS}

Induction Abortion Interval, Mifepristone, Misoprostol.

HOW TO CITE THIS ARTICLE: Nath AG, Kumar A. On efficacy and acceptability of early medical abortion by mifepristone with oral or vaginal misoprostol. J. Evolution Med. Dent. Sci. 2017;6(66):4757-4760, DOI: 10.14260/Jemds/2017/1030

\section{BACKGROUND}

Unsafe abortion is a major public health problem in developing countries. Globally, 20 million unsafe abortions take place each year and account for $13 \%$ of all maternal deaths. (1)

The incidence of induced abortions is not definitely known, because estimates of illegal abortions are generally unreliable. This has led to the liberalisation of abortion laws and search for newer methods.

Medical abortion offers great potential for improving abortion access and safety. The drugs used were mainly mifepristone (RU 486), a potent antiprogestin in combination with prostaglandin $\mathrm{E}_{1}$ analogue misoprostol.

Financial or Other, Competing Interest: None.

Submission 11-07-2017, Peer Review 07-08-2017,

Acceptance 12-08-2017, Published 17-08-2017.

Corresponding Author:

Dr. Asha Gopi Nath,

Neelambari,

Udayanapuram P.O,

Vaikom, Kottayam-686143.

E-mail: drgnathasha@gmail.com

DOI: $10.14260 /$ jemds $/ 2017 / 1030$
It has been in use for over a decade and research is ongoing since its inception. But still in 2012, WHO and the Guttmacher Institute reported that $56 \%$ of abortions in developing countries were unsafe.(2)

Mifepristone $200 \mathrm{mg}$ was found to be as effective as 600 mg in multicentre trials by WHO.(3) Studies have also shown that vaginal administration of misoprostol after pretreatment with mifepristone resulted in higher complete abortion compared to oral dose.(4) The present study was undertaken to compare the efficacy, acceptability, side effects and factors affecting outcome of early medical abortion with oral and vaginal misoprostol after oral mifepristone in inducing medical abortion up to 49 days. Increasing access to safe abortion services is the most effective way of preventing unsafe abortions. ${ }^{(5)}$

\section{MATERIALS AND METHODS}

This interventional study (non-RCT) was conducted on women requesting termination of early pregnancy $\leq 49$ days in the outpatient department of family planning unit for a period of one year. Women seeking MTP with USG confirmed intrauterine pregnancy; $<35$ years and who were able to come for one to three follow-ups were selected for the study. 
Women with suspected/ confirmed ectopic pregnancy, IUCD, hypersensitivity to drugs with medical complications and previous scar on uterus were excluded.

Based on a pilot study, the mean induction abortion interval for the Group I (Oral) was $4.01 \pm 2.7$ and in the Group II (Vaginal) was $3.12 \pm 1.2$. The following formula was used to estimate the minimum sample size.

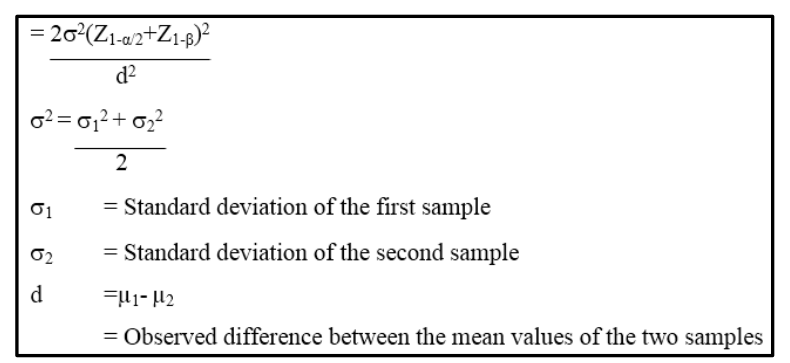

\section{Substituting the Values}

Standard deviation in Group I

Standard deviation in Group II

Mean difference

Effect size

Alpha error (\%)

Power (1-beta) \%

1 or 2 sided

Required minimum sample size per group

Ethical committee approval was obtained. After getting an informed written consent, patients satisfying inclusion criteria were allocated alternately into Group I (Oral) and Group II (Vaginal). They were counselled regarding procedure characterisation like cost, efficacy, safety, number of visits and probable need of a surgical abortion.

On Day 1, both groups received $200 \mathrm{mg}$ of mifepristone. They were also observed in OP and allowed to go home. If abortion had not occurred in 48 hours, Group I was given 400 $\mathrm{mg}$ ( 2 tablets) of misoprostol orally. Group II received $800 \mathrm{mg}$ (4 tablets) of misoprostol vaginally. Women were observed for 4 hours. They were asked to keep record of onset of bleeding, time of expulsion of products and any side effects noted. They were given a telephone number to contact when concerned.

All the women were reviewed on Day 14 with repeat USG and $\mathrm{Hb}$ estimation. They were enquired about the degree of satisfaction, whether they will use it for a second time if needed and whether they would suggest it to their friends.

Outcome was measured as complete abortion (requiring no surgical intervention), incomplete abortion (clinical and USG evidence), missed abortion and ongoing pregnancy. Success was defined as expulsion of products of conception with no need for surgical intervention. Induction abortion interval was defined as the time interval in hours from the administration of misoprostol to the passing of products of conception.

Quantitative variables were analysed by ' $\mathrm{t}$ ' test and qualitative variable by $\mathrm{X}^{2}$ test. $\mathrm{P}<0.05$ was taken as significant.

RESULTS

Table I. Demographic Profile of Both Groups

\begin{tabular}{|c|c|c|c|c|c|c|}
\hline \multirow{2}{*}{ Age in Years } & \multicolumn{2}{|c|}{ Group I } & \multicolumn{2}{c|}{ Group II } & \multicolumn{2}{c|}{ Total } \\
\cline { 2 - 7 } & No. & $\mathbf{\%}$ & No. & \% & No. & \% \\
\hline$<20$ & 6 & 5.89 & 3 & 2.97 & 9 & 4.43 \\
\hline $21-25$ & 49 & 48.04 & 36 & 35.64 & 85 & 41.87 \\
\hline $26-30$ & 30 & 29.41 & 34 & 33.66 & 64 & 31.52 \\
\hline $31-35$ & 17 & 16.67 & 28 & 27.72 & 45 & 22.16 \\
\hline
\end{tabular}

Table Ia. Distribution according to Age

$\chi^{2}=0.1154 ; \mathrm{p}>0.05$

Table Ia. Distribution According to Age

In the present study majority of patients come under 21-25yr age group (41.87\%) followed by the 26 -30yrs age group (31.52\%). In <20 age group it was $5.89 \%$ in Group I and $2.97 \%$ in Group II and in 31-38yrs age group it was $16.67 \%$ in Group I and $27.72 \%$ in Group II. Both groups are comparable with respect to age.

\begin{tabular}{|c|c|c|c|c|c|c|}
\hline \multirow{2}{*}{ Parity I } & \multicolumn{2}{|c|}{ Group I } & \multicolumn{2}{c|}{ Gotal } \\
\cline { 2 - 7 } & $\mathbf{N o .}$ & $\mathbf{\%}$ & No. & $\mathbf{\%}$ & No. & \% \\
\hline Primi & 4 & 3.92 & 6 & 5.94 & 10 & 4.93 \\
\hline Para 1 & 70 & 68.63 & 59 & 58.41 & 129 & 63.55 \\
\hline Para 2 & 28 & 27.45 & 36 & 35.64 & 64 & 31.53 \\
\hline Total & $\mathbf{1 0 2}$ & $\mathbf{1 0 0}$ & $\mathbf{1 0 1}$ & $\mathbf{1 0 0}$ & $\mathbf{2 0 3}$ & $\mathbf{1 0 0}$ \\
\hline \multicolumn{6}{c|}{ Table Ib. Distribution according to Parity } \\
$\chi^{2}=0.311 ; p>0.05$
\end{tabular}

Table Ib. Distribution According to Parity

Multipara constituted $96.08 \%$ cases in Group I and 94.05 cases in Group II whereas primis constituted 3.92\% and 5.94\% in Group I \& II respectively. Both groups were found to be comparable after applying the Chi-square test.

\begin{tabular}{|c|c|c|c|c|c|c|}
\hline Gestational & \multicolumn{2}{|c|}{ Group I } & \multicolumn{2}{c|}{ Group II } & \multicolumn{2}{c|}{ Total } \\
\cline { 2 - 7 } Age in Days & No. & $\mathbf{\%}$ & No. & $\mathbf{\%}$ & No. & \% \\
\hline $35-42$ & 65 & 63.72 & 55 & 54.45 & 120 & 59.12 \\
\hline $43-49$ & 37 & 36.27 & 46 & 45.54 & 83 & 40.88 \\
\hline Total & $\mathbf{1 0 2}$ & $\mathbf{1 0 0}$ & $\mathbf{1 0 1}$ & $\mathbf{1 0 0}$ & $\mathbf{2 0 3}$ & $\mathbf{1 0 0}$ \\
\hline & Table Ic. Distribution according to Gestational Age \\
\hline & $\chi^{2}=1.8 ; p>0.05$
\end{tabular}

\section{Table Ic. Distribution According to Gestational Age}

Both groups are comparable with respect to gestational age.

$76.3 \%$ were residing in urban area and $23.3 \%$ in rural area. $79.8 \%$ were from middle socioeconomic group. $91.6 \%$ had high school or higher level of education. $86.2 \%$ were housewives. 92.6\% were married. 98\% induced abortions were on social grounds $91.6 \%$ had complete abortion. Check curettage was done for $8.3 \%$ with incomplete abortion. There were no cases of missed abortion or continuing pregnancy. Complete abortion was $91.1 \%$ for Group I oral and $92 \%$ for Group II vaginal $(\mathrm{P}=0.816)$ showing both routes were equally effective.

\begin{tabular}{|c|c|c|c|c|c|c|}
\hline \multirow{2}{\text{Induction}}{$\begin{array}{c}\text { Indion I } \\
\text { Abortion Interval }\end{array}$} & \multicolumn{2}{|c|}{ Group } & \multicolumn{2}{c|}{ Gotal } \\
\cline { 2 - 7 }$\leq 4 \mathrm{hrs}$. & 80 & 78.43 & 91 & 90.09 & 171 & 84.24 \\
\hline$>4$ hrs. & 22 & 21.57 & 10 & 9.90 & 32 & 15.76 \\
\hline Table II. Comparison of Induction-Abortion \\
Interval between the Two Groups \\
\hline
\end{tabular}

Table II Comparison of induction- abortion interval between the two groups. 


\begin{tabular}{|c|c|c|c|c|}
\hline $\begin{array}{c}\text { Induction Abortion } \\
\text { Interval }\end{array}$ & Mean & SD & 't' Value & P Value \\
\hline Group I & 4.29 & 2.5 & 2.52 & $0.01 \mathrm{~S}$ \\
\hline Group II & 3.5 & 1.6 & & \\
\hline Table III. Mean Induction Abortion Interval \\
\hline
\end{tabular}

Table III Mean Induction Abortion Interval

The mean induction abortion interval was 4.29 hours for oral group and 3.5 hours for vaginal groups. $78.4 \%$ in oral group had induction abortion interval $\leq 4$ hours compared to $90 \%$ in vaginal group. Factors affecting induction abortion interval was studied. There was no statistically significant association with age, parity and gestational age. In both groups those with a history of previous abortion had a failure rate of $33.3 \%$ $(\mathrm{P}=0.000$ and $\mathrm{P}=0.007$ respectively in oral and vaginal groups)

\begin{tabular}{|c|c|c|c|c|c|c|c|c|}
\hline \multirow{2}{*}{ Age in Years } & \multicolumn{2}{|c|}{ Group I } & \multicolumn{2}{|c|}{ Group II } & \multicolumn{2}{|c|}{ Total } & \multirow{2}{*}{$\chi^{2}$} & \multirow{2}{*}{ P Value } \\
\hline & No. & $\%$ & No. & $\%$ & No. & $\%$ & & \\
\hline Nausea & 25 & 24.51 & 8 & 7.92 & 33 & 16.26 & 7.41 & $<0.05 \mathrm{~S}$ \\
\hline Vomiting & 14 & 13.73 & 5 & 4.95 & 19 & 9.36 & 3.8 & $<0.05 \mathrm{~S}$ \\
\hline Diarrhoea & 6 & 5.88 & 3 & 2.97 & 9 & 4.43 & 0.34 & $>0.05 \mathrm{NS}$ \\
\hline Abdominal Pain & 88 & 83.27 & 83 & 82.18 & 171 & 84.24 & 0.64 & $>0.05 \mathrm{NS}$ \\
\hline Fatigue & 51 & 50 & 34 & 33.66 & 85 & 41.87 & 5.56 & $<0.05 \mathrm{~S}$ \\
\hline & & & $\mathrm{Com}$ & of Sid & $S P r$ & & & \\
\hline
\end{tabular}

\section{Table IV. Comparison of Side Effect Profile}

Statistically established differences were noted in the occurrence of nausea, vomiting and fatigue between the two groups. Among the major side effect nausea (24\%), vomiting $(13.7 \%)$ and fatigue $(50 \%)$ were significantly more in oral group.

\begin{tabular}{|c|c|c|c|c|}
\hline $\begin{array}{c}\text { Duration of } \\
\text { Bleeding in Days }\end{array}$ & Mean & SD & ' $\mathbf{t}$ ' Value & P Value \\
\hline Group I & 9.38 & 2.5 & \multirow{2}{*}{3.49} & $<0.000 \mathrm{~S}$ \\
\hline Group II & 8.2 & 1.87 & & \\
\hline \multicolumn{5}{|c|}{ Table V. Mean duration of Bleeding } \\
\hline
\end{tabular}

\section{Table V Mean duration of Bleeding}

Mean duration of bleeding was significantly less in Group II compare Group I ( $\mathrm{P}=0.000)$. Mean $\mathrm{Hb}$ drop was not clinically significant between two groups. The average duration of bleeding was $9.37 \pm 2.5$ days with oral group and $8.28 \pm 1.8$ in vaginal group which was similar other studies. 3,4

\begin{tabular}{|c|c|c|c|c|c|c|}
\hline \multirow{2}{*}{ Acceptance } & \multicolumn{2}{|c|}{ Group I } & \multicolumn{2}{|c|}{ Group II } & \multirow{2}{*}{$\chi^{2}$} & \multirow{2}{*}{$\begin{array}{c}\mathbf{P} \\
\text { Value }\end{array}$} \\
\hline & No. & $\%$ & No. & $\%$ & & \\
\hline Satisfied & 94 & 92.2 & 86 & 85.1 & 2.4 & \multirow{3}{*}{$>0.05$} \\
\hline \begin{tabular}{|c|}
$\begin{array}{c}\text { Will use the same } \\
\text { method }\end{array}$ \\
\end{tabular} & 92 & 90.2 & 86 & 85.1 & 1.2 & \\
\hline $\begin{array}{l}\text { Will suggest to } \\
\text { friends }\end{array}$ & 92 & 90.2 & 86 & 85.1 & 1.2 & \\
\hline
\end{tabular}

Table VI. Distribution according to Level of Acceptance

Table VI. Distribution According to Level of Acceptance Method satisfaction was more among oral group $92.2 \%$ compared to $85 \%$ vaginal. Acceptance is further reflected by the fact that $90 \%$ of oral group and $85 \%$ in vaginal group were willing to accept to the method again and if needed the same $\%$ would suggest it to their friends.

\section{DISCUSSION}

In our study mean age was 26.2 which is comparable to other studies.6,7 There was no association of complete abortion rate with gestational age or parity. In a WHO Multi national study of 2219 women with gestational age $<63$ days parity significantly affected the percentage of complete abortion ${ }^{3}$ Complete abortion was $91.1 \%$ for Group I oral and 92\% for Group II vaginal $(\mathrm{P}=0.816)$ showing both routes were equally effective. Similar efficacy in oral and vaginal routes were noted in studies by Peyron et $\mathrm{al}^{9}$ and Nitya et $\mathrm{al}^{6}$. Schaff et al in randomized trial have found the complete abortion with oral group to be $95 \%$ as against $99 \%$ in the vaginal groups. ${ }^{10}$ The mean induction abortion interval was 4.29 hours for oral group and 3.5 hours for vaginal groups. $78.4 \%$ in oral group had induction abortion interval $\leq 4$ hours compared to $90 \%$ in vaginal group which is comparable to the study by el Refaey et al ${ }^{4}$. Shorter induction abortion interval in vaginal group may be because of the long lasting and continuously increasing uterine contractility of vaginal misoprostol. ${ }^{11}$ In both groups those with a history of previous abortion had a failure rate of $33.3 \%$ ( $\mathrm{P}=0.000$ and $\mathrm{P}=0.007$ respectively in oral and vaginal groups). Premila et al in a study of factors affecting outcome of early medical abortion with review of 4132 consecutive cases of have found out that those who had a previous abortion were more likely to have a failed medical abortion ( $\mathrm{OR}=2.09)^{8}$. The average duration of bleeding was $9.37 \pm 2.5$ days with oral group and $8.28 \pm 1.8$ in vaginal group. This was similar to studies by el Refaey et al 4 . W H O studies showed 11-12 days bleeding3. Among the major side effect nausea (24\%), vomiting (13.7\%) and fatigue (50\%) were significantly more in oral group. Studies by Schaff et al ${ }^{10}$ and el-Refaey ${ }^{4}$ also showed increased vomiting in oral group compared to vaginal. The latter study ${ }^{4}$ also note fatigue as a major side effects in both groups $(67 \%$ in oral and $70 \%$ in vaginal). There were no major adverse events in this study as in others studies. 4,9

Method satisfaction was more among oral group $92.2 \%$ compared to $85 \%$ vaginal. Acceptance is further reflected by the fact that $90 \%$ of oral group and $85 \%$ in vaginal group were willing to accept to the method again and if needed the same \% would suggest it to their friends. Similar acceptability rates were seen in studies by Schaff et al ${ }^{10}$ whereas Winikoff et $\mathrm{a}^{12}$ evaluated acceptability of Mifepristone and Misoprostol regimen and found that it was highly acceptable and $96 \%$ would recommend it to others and 91\% would choose it again. 


\section{CONCLUSION}

It is evident from the present study that both oral and vaginal routes of misoprostol had similar efficacy in early pregnancy termination up to 49 days. Medical abortion can be safely propagated and can replace surgical abortion in the coming years in view of its efficacy and acceptability as shown in the present study. Moreover, women can exercise their choice of the method which will ensure the acceptability and thus decreasing unsafe abortions and related morbidity.

\section{ACKNOWLEDGEMENTS}

We are extremely thankful to Dr. C P Vijayan, Professor, Head of the Department of Obstetrics and Gynaecology for the valuable suggestions and guidance. We also thank faculty members of family planning unit and all the patients who participated in the study. We also express our sincere thanks to Dr. K Babu, Associate Professor of Statistics and Demography.

\section{REFERENCES}

[1] WHO: Unsafe abortion: global and regional estimated of incidence of unsafe abortion and associated mortality in 2003, Geneva: World Health Organisation, 2007.

[2] Guttamacher Institute and WHO. facts on induced abortion world-wide. Fact sheet. Geneva, WHO, 2012. https://www.guttmacher.org/fact-sheet/factsinduced abortion-world-wide.

[3] World Health Organisation Task Force on Postovulatory Methods of Fertility Regulation 1, Special Programme of Research, Development and Research Training, World Health Organisation. Comparison of two doses of mifepristone in combination with misoprostol for early medical abortions: a randomized trial. BJOG 2000;107(4):524-30.
[4] el-Refaey H, Rajasekar D, Abdalla M, et al. Induction of abortion with mifepristone (RU 486) and or vaginal misoprostol. N Engl J Med 1995;332(15):983-7.

[5] Berer M. Medical abortion: issues of choice and acceptability. Reproductive Health Matters 2005;13(26):25-34.

[6] Nithya J, Reddi RP. Comparison of oral and vaginal misoprostol after oral mifepristone in earl medical abortion. Int J Reprod Contracept Obstet Gynecol 2017;6(3):1007-11.

[7] Mittal S, Agrwal S, Kumar S, et al. Comparison of oral versus vaginal misoprostol \& continued use of misoprostol after mifepristone for early medical abortion. Indian J Med Res 2005;122(2):132-6.

[8] Peyron R, Aubeny E, Targosz V, et al. Early termination of pregnancy with mifepristone (RU 486) and the orally active prostaglandin misoprostol. N Eng J Med 1993;328(21):1509-13.

[9] Schaff EA, Fielding SL, Westhoff C. Randomized trial of oral versus vaginal misoprostol at one day after mifepristone for early medical abortion. Contracep 2001;64(2):81-5.

[10] Dannielson KG, Marons L, Rodriguez A, et al. Comparison between oral and vaginal administration of misoprostol on uterine contractility. Obstet Gynecol 1999;93(2):275-80.

[11] Ashok PW, Templeton A, Wagaarachchi PT, et al. Factors affecting the outcome of early medical abortion: a review of 4132 consecutive cases. BJOG 2002;109(11):1281-9.

[12] Wnnikoff B, Ellertson C, Elul B, et al. Acceptability and feadibility of early pregnancy termination by mifepristone-misoprostol. Results of a large multicenter trial in the United States. Mifepristone Clinical Trials Group. Arch Fam Med 1998;7(4):360-6. 